\title{
Calculation of filtration process in channels
}

\author{
Aybek Arifjanov", Luqmon Samiev, Ifoda Ahmedkhodjaeva, Qudratjon Rakhimov and \\ Shokhrux Sobirov \\ Tashkent Institute of Irrigation and Agricultural Mechanization Engineers, Tashkent, Republic of \\ Uzbekistan
}

\begin{abstract}
This article provides an analysis and recommendations of the factors that lead to the loss of water as a result of filtration in uncoated canals, rising groundwater levels, deterioration of land reclamation, reduction of canal efficiency coefficient. According to the project data, the part of the Greater Fergana canal from PK-930 to PK-1500 + 10 was built in the type of semi-excavated and natural canal. From PK-930 to PK-1040, the ground level is almost equal to the bottom water level, and the volume of soil discharged in this part of the canal is greater than in other parts. The canal is in the form of a trapezoid and has now changed its shape slightly as a result of a small amount of sedimentation and erosion. In uncoated canals and irrigation systems, there are a number of connections to perform the basic filtration calculation. These bonds are obtained according to Darcy's law, filtration for homogeneous and isotropic soils. Using the available data, it is possible to determine the depression curve in canals and irrigation systems for all cases, the points that form its curvature, and the filtration rate that occurs in it. It consists of determining the filtration rate (q) of the system at a length of 1 pogm and the filtration coefficient (k) of the soil.
\end{abstract}

\section{Introduction}

At present, one of the most pressing issues in the implementation of economic reforms is to increase the efficiency of large waterways, reduce their maintenance and operating costs. Currently, soil channels are more common in the country and have a number of shortcomings: first, the channel has a sedimentation and erosion - washing process (hence they are called "deformable channels"), sedimentation changes the permeability of the channel as a result, the ability to deliver the required amount of water to the consumer at the right time is reduced, secondly, filtration processes require in-depth research, which complicates the operation of the irrigation system, worsens soil reclamation and large water wastage. Therefore, the problem of camaraderie operation of main and farm internal canals requires a detailed study of the dynamics of water and solid particle flow in the canals $[1,2,3,4]$.

Organizing targeted and rational use of water resources based on the introduction of market principles and mechanisms of water use, introduction of advanced technologies,

* Corresponding author: obi-life@mail.ru 
organization of uninterrupted and timely supply of water to consumers, ensuring technical reliability of irrigation systems and water facilities, water important tasks such as rational management of resources, ensuring accurate accounting and reporting of water resources use.

Therefore, it is important to determine the efficiency of the main canals in the country and develop measures to increase it $[5,6,7]$.

\section{Initial data and research methods.}

In uncoated canals and irrigation systems, there are a number of connections to perform the basic filtration calculation. These bonds were obtained according to Darcy's law of filtration for homogeneous and isotropic soils. Using the available data, it is possible to determine the depressive curve in the canals and irrigation systems for all cases or the points that form its curvature and the filtration flow in it. It consists of determining the filtration rate (q) of the system at a length of 1 pog.m and the filtration coefficient $(k)$ of the soil. Determining the filtration rate in the channels is as follows $[8,9]$ :

$$
Q=k \cdot q_{u} \cdot L
$$

$q H$ - relative filtration rate; $L$ - is the length of the channel; $\kappa$ - is the filtration coefficient.

The following formulas can be used for homogeneous anisotropic soils in addition to homogeneous and isotropic soils. In this case, the filtration coefficient is equal to $\mathrm{kg}$ in the horizontal direction and $\kappa \beta$ in the vertical direction. For this, need to increase the anisotropic fraction to horizontal dimensions to $\sqrt{K_{s}}$. Filtration discharge for anisotropic soils can be determined by the following formula:

$$
Q=\sqrt{k_{B}} \cdot k_{\Gamma} \cdot q_{u} \cdot L
$$

The cross-section of the channel, which has a relatively high water permeability of the bottom layer, corresponds to the trapezoidal channels. This is because the wetting perimeter of this surface is the largest. The pressure in the lower permeable upper layer is equal to $H_{0}$ and the affected $H$. when the pressure in a strongly permeable layer is $H_{0}=0$ it will $q_{4}=B+A h$. In this case, the width of the maximum filtration flow $[10,11,12]$.

$$
q_{4}=L
$$

For calculation filtration discharge in the channel under field conditions, determines the flow discharge $\mathrm{Qa}$ in $\mathrm{A}$ point and determines water discharge $\mathrm{QB}$ at point $\mathrm{B}$, and the relative filtration consumption for this section is determined as follows:

$\boldsymbol{L}$ - is the length of the plot, $m$

$$
q_{4}=\frac{Q_{A}-Q_{B}}{L}
$$

If the filtration coefficient is known and the solid layer is close to the bottom of the channel, the relative filtration discharge in the stack can be determined by the following formula:

$$
q_{4}=\frac{k \cdot\left(h_{1}^{2}-h_{2}^{2}\right)}{2 L}
$$

$q_{4}$ - relative filtration discharge; $h_{1}, h_{2}$ - are the flow depths at sections $1-1$ and 2-2 which located at a distance $\mathrm{L}$ from each other.

The above two equations need to be solved by the approximation method. When the symmetrical pressure filtration in the channels and the solid layer are located at very deep depths, the coordinates of the dispersion curve can be determined as follows $[13,14,15,16]$ : 


$$
y=0,73 \cdot q_{u} \cdot \lg \left(A+\sqrt{\left.A^{2}-1\right)}\right.
$$

there,

$$
A=\frac{2 x-q_{4}}{B-q_{u}}
$$

as a result, the relative filtration dischargee is determined as follows:

$$
q_{u}=\frac{y}{0,73 \cdot \lg \left[\frac{2 x-q_{u}}{B-q_{u}}+\sqrt{\left(\frac{2 x-q_{u}}{B-q_{u}}\right)^{2}-1}\right]}
$$

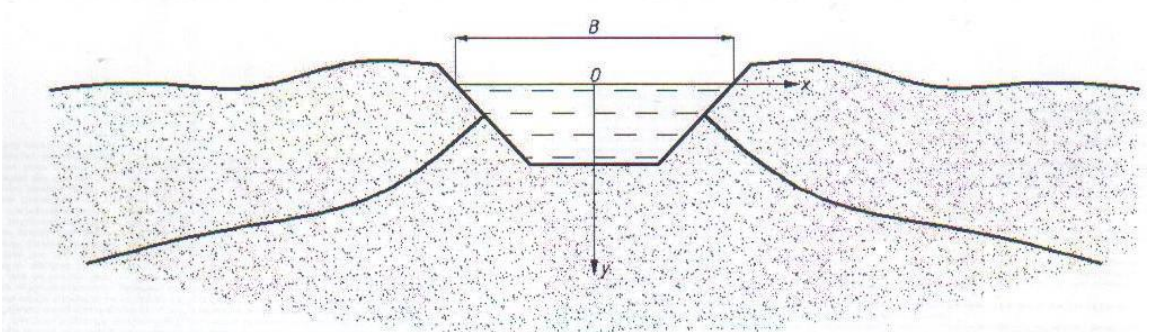

Fig. 1. Determination of filtration (water leakage) from channels. (Formulas given in QMCh 2.06.0397)

Calculation of water leakage loss from constantly moving, ground-free free-flowing canals should be performed on the following connections:

a) for polygonal and parabola channels:

$$
Q_{f}=0.0116 k_{f}\left(B+2 d_{c}\right)
$$

б) for channels with a trapezoidal shape which equal to $\frac{b}{d_{c}}<4$

$$
Q_{f}=0.0116 k_{f} \mu\left(B+2 d_{c}\right)
$$

If is $\frac{b}{d_{c}}>4$

$$
Q_{f}=0.0116 k_{f}\left(B+A d_{c}\right)
$$

there: $Q_{f}=1 \mathrm{~km}$ of canal length leakage water discharge, $\mathrm{m}^{3} / \mathrm{s}$ $k_{f}$ - coefficient of soil erosion below the channel, $\mathrm{m} / \mathrm{sum}$

$\mathrm{B}$ - is the width of the canal along the water section, $\mathrm{m}, \mathrm{b}$ - is the width along the bottom of the canal,m, $\quad d_{c}$ - is the depth of water in the canal, $\mathrm{m}$ $\mu$ and $\mathrm{A}$ - coefficients, (determined according to the table).

If the foundation is multi-layered, the coefficient of filtration should be determined by the following formula: 


$$
k_{f}=\frac{t_{1}+t_{2}+\ldots+t_{n}}{\frac{t_{1}}{k_{1}}+\frac{t_{2}}{k_{2}}+\ldots \frac{t_{n}}{k_{n}}}
$$

there: $f_{1} \ldots f_{n}$ - thickness of layers, $\mathrm{m}$

$k_{1} \ldots k_{n}-$ leakage coefficient of the soil layer, $\mathrm{m} / \mathrm{sum}$

It is recommended to calculate the leakage loss from the covered channels, per $1 \mathrm{~km}$ $\mathrm{m}^{3} / \mathrm{s}$, when the mountains and slopes are covered with a coating of the same thickness and the installed free leakage according to the formula [4,5]:

$$
Q_{f}=0.0116 \frac{k_{s}}{t}\left[b\left(d_{c}+t\right)+2 d_{c}\left(\frac{d_{c}}{2}+\frac{m t}{\sqrt{1+m^{2}}}\right)\right] \overline{1+m^{2}}
$$

there : $k_{s}$ - the coefficient of filtration of the curtain (barrier), $\mathrm{m} / \mathrm{sum}$

$\mathrm{t}$ - is the thickness of the coating, $\mathrm{m}, \mathrm{b}$ - is the width of the bottom of the channel, $M$ $d_{c}$ - calculated water discharge, canal filling depth, $\mathrm{m}$ $\mathrm{m}-$ slope coefficient.

The wastage of the obstructed leak should be taken into account in linked $Q_{n}=f Q_{f}$,

there: $Q_{f}$ - leakage wastage in free leakage $\mathrm{m}^{3} / \mathrm{s}$

a - coefficient is the effect of groundwater barrier property on leakage loss $(a<1)$, the channel horizon, the rise of groundwater from the horizon height and is determined on the basis of the table.

\section{Results and analysis}

For the analysis of the results obtained on the basis of the above calculation formulas, the part of the Northern Fergana Canal (NFC) from PK $0+00$ to PK $488+00$ and the part of additional water intake from PK $0+00$ to PK $130+20$, PK $282+40$ to PK $442+20$ were analyzed and recommendations were given.

The operation department of the canal from PK $488+00$ to PK $2497+00$ is located in Fergana. It is carried out by the Greater Fergana Main Canal Authority [17,18,19].

Hydraulic parameters (projection) of the surveyed part of BFC (Big Fergana Channel)

\begin{tabular}{|c|c|c|c|}
\hline \multirow[b]{2}{*}{ Channel section } & \multicolumn{3}{|c|}{$\mathrm{BFC}$} \\
\hline & PC $930+00$ & PC $1500+10$ & PC $1710+00$ \\
\hline $\begin{array}{c}\text { Maximum water discharge, } \\
\mathrm{m}^{3} / \mathrm{s}\end{array}$ & 130 & 75 & 73 \\
\hline length , km & 77 & 21 & 21 \\
\hline Width of water level, m & 32,1 & 30,8 & 34,7 \\
\hline Width of bottom, m & 24,1 & 18,1 & 17.4 \\
\hline Water velocity, $\mathrm{m} / \mathrm{s}$ & 0,73 & 1,05 & 1,05 \\
\hline
\end{tabular}

Table 1 
Depth (maximum),

Depth, m

Qmin depth, m

The slope coefficien

Slope

UWC

$$
\begin{gathered}
3,00 \\
2,75 \\
\text { n.s } \\
1,5 \\
0,00015 \\
0,86
\end{gathered}
$$

3,00

2,80

n.s

1,8

0,00014

0,86

According to the project data, the part of the Greater Fergana canal from PK-930 to PK$1500+10$ was built in the type of semi-excavated and semi-natural canal. Especially in PK930 to PK-1040, the ground level is almost equal to the lower water level, and the volume of soil discharged in this part of the canal is greater than in other parts. The canal is trapezoidal in shape and changed its shape slightly as a result of a small sedimentation and erosion (Figure 3) [20,21,22]. This can be clearly seen in the line diagram of the project and actual scheme of the channel.

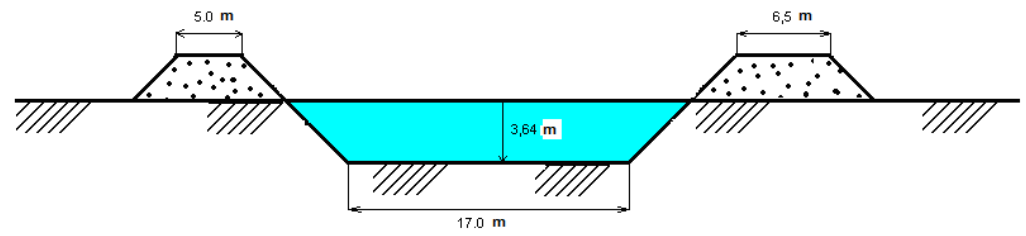

Fig. 2. Cross section of the channel (according to the project PK-1257+27 - PK-1600)

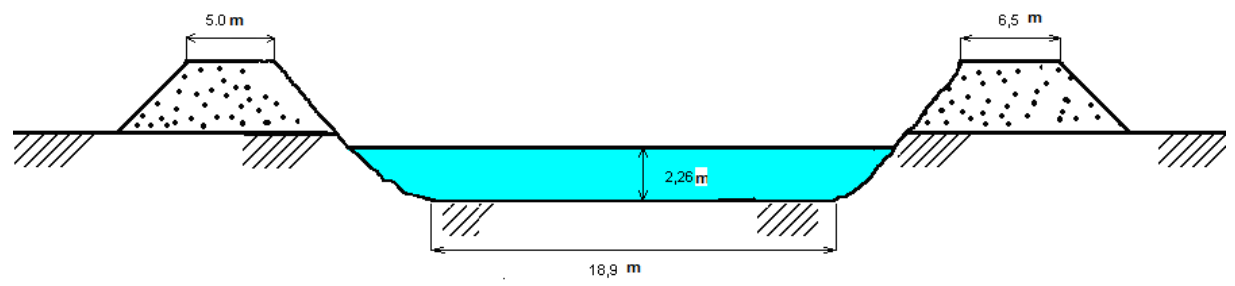

Fig. 3. Cross section of the channel (based on measurements PK-1510)

Calculated parameters of water discharge and UWC of the Greater Fergana canal in section 3 (PK-930 and PK-1500)

\begin{tabular}{cccc}
\hline Month & Decades & $\begin{array}{c}\text { Water dischage } \\
\mathbf{Q}, \mathbf{~ m}^{\mathbf{3}} / \mathbf{s}\end{array}$ & $\begin{array}{c}\text { Useful operation } \\
\text { coificient (UWC) }\end{array}$ \\
\hline \multirow{3}{*}{ April } & I & 57,43 & 0,90 \\
& II & 57,83 & 0,92 \\
& III & 54,34 & 0,97 \\
\multirow{3}{*}{ May } & I & 57,06 & 0,93 \\
& II & 59,52 & 0,94 \\
& III & 57,52 & 0,94 \\
\multirow{3}{*}{ June } & I & 48,75 & 0,95 \\
& II & 57,01 & 0,94 \\
& III & 62,15 & 0,92
\end{tabular}

Table 2 


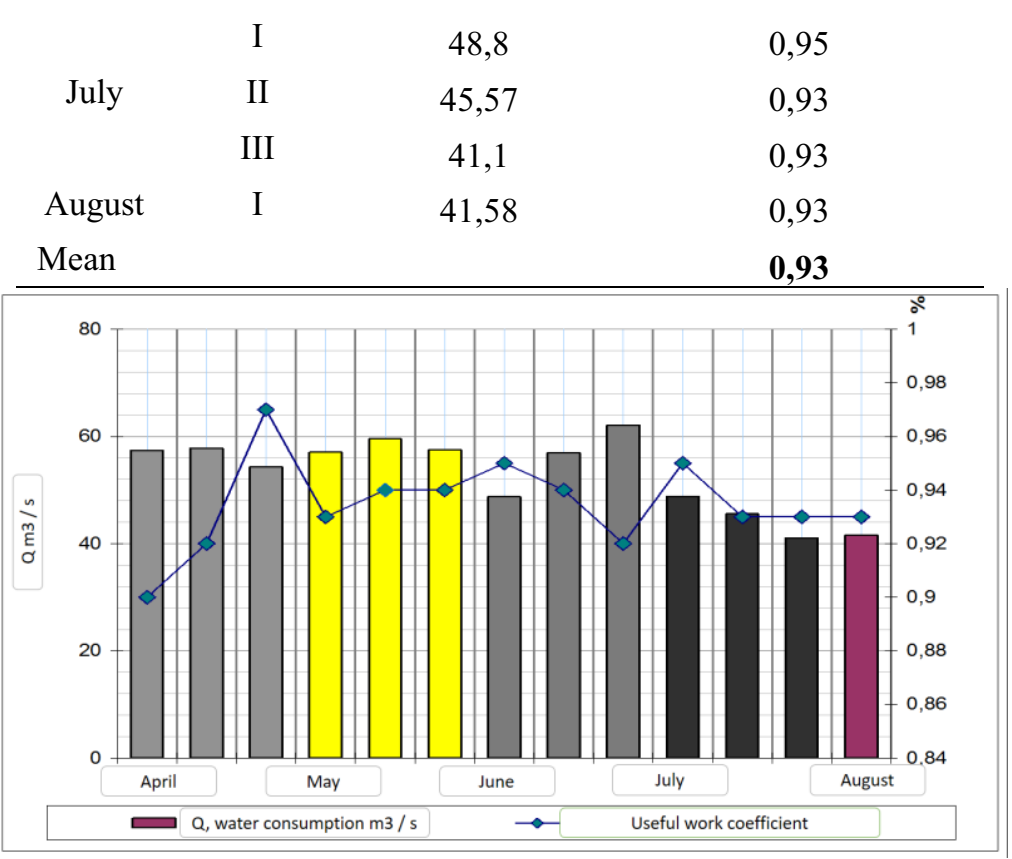

Fig. 4. NFCs water dischargeconsumption and UWC in section 3 (PK-930 and PK-1500)

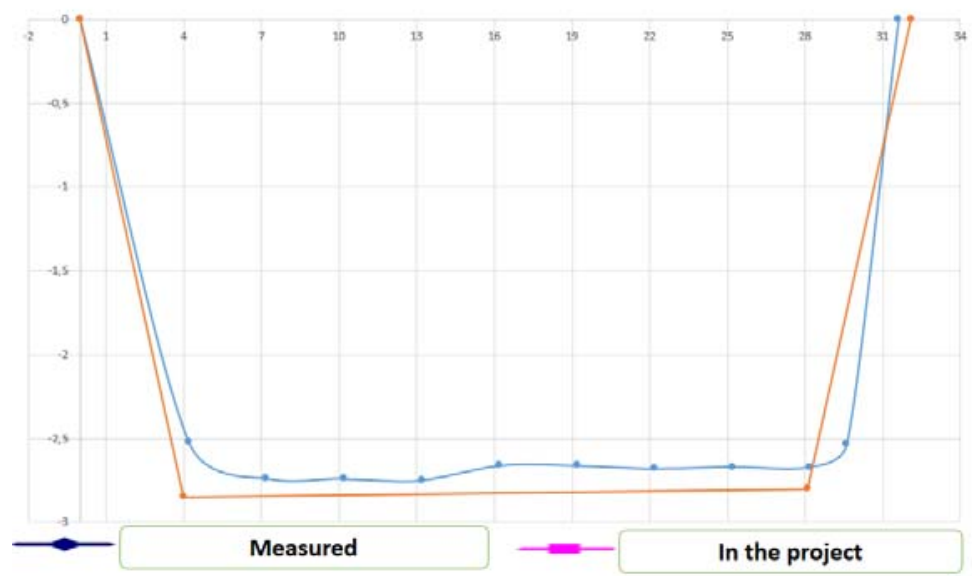

Fig. 5. Canal section at the hydro post (PK-930

\section{Conclusion}

The following conclusions and recommendations can be made from the research. Over the years, the channel has been colmatized under the influence of fine particles (sediments) because of the significant amount of turbidity in the channel.

Studies at the head of the canal have shown that the sediments are filled with mud and the turbidity is passing into the canal;

during the growing season, groundwater rises and filtration decreases to a certain extent, on the other hand, the proximity of groundwater causes salinization of soils in some places;

the amount of water in the canal changes as the water level in the canal changes; 
when the water level in the canal decreases, the water consumption in the canal increases due to groundwater;

studies over the years have shown that the amount of filtration in the upstream part of the canals is significant.

The FIK content is relatively high in the excavated parts of the canal;

As a result of the research, it was found that when the water level in the canal decreases, drainage water is added to it. As a result, the channel FIC is approaching $\bar{e}=0.98$. This process needs to be studied separately;

to increase the water permeability of the canal, it is necessary to regularly clean the banks of the canal from vegetation;

During the many years of operation of the canal, there was a natural collimation with a certain amount of fine lacquer particles. However, during the period when the water level in the canal decreases, the canal slopes dry up and cracks appear again. Therefore, abrupt level changes in the channel should be minimized;

The loss of water in the canals as filtration leads to an increase in groundwater levels, deterioration of land reclamation, a decrease in the FIC of the canal, which in turn leads to an increase in operating costs and disturbance of the ecological balance.

\section{References}

1. Pavchich M.P., Balykov B.I. Methods for determining the coefficient of filtration of soils. - M .: Energiya, 1976. - 115 p

2. Karimov R.M. Gidravlicheskiy raschet kanalov (uchebnoe posobie), Tashken, 1976, izd. "Uzgiprozem".

3. Jurayev, Sh. Sh. (2019). Analyze the permeability of bentonite and sand in soil structures // ISJ Theoretical \& Applied Science, Philadelphia, USA. 03 (71), -Rr.437440 .

4. Jurayev Sh. Determination of water permeability of local ground in field conditions // Indo - Asian Journal of Multidisciplinary Research, 2019, 5 (1): -Rr.1592 - 1596.

5. Rauschenbakh I.O. About the distribution of mudflows in the territory of Central Asia and Kazakhstan. // Issues of studying mudflows // Proceedings of KazNIGMI. - M .: Hydrometeoizdat, 1969. - Issue. 33 .-- S. 131.

6. Arifzhanov, A.M. Method for calculation of the distribution of drift particles in variable section beds (VSB) (2004) Gidrotekhnicheskoe Stroitel'stvo, (2), pp. 44-45.

7. Arifzhanov, A.M. Distribution of Suspended Sediment Particles in a Steady-State Flow. (2001) Water Resources, 28 (2), pp. 164-166. DOI: 10.1023/A:1010375500148

8. Kirenskaya T.L., Danilina N.A. On long-term forecasts of mudflow phenomena of storm origin // Mudflows. - M., Hydrometeorological Publishing House, 1989. - Sat. 11. - P. 27.

9. Lyakhovskaya L.F. Mudflow hazard in the foothills of Uzbekistan and its short-term forecast: Author's abstract. dis. ... Cand. geogr. Sciences: 11.00.07. - T., 1989 .-- 42 p.

10. Samiyev, L., Allayorov, D., Atakulov, D., Babajanov, F. The influence of sedimentation reservoir on hydraulic parameters of irrigation channels (2020) IOP Conference Series: Materials Science and Engineering, 883 (1), DOI: 10.1088/1757899X/883/1/012031

11. Arifjanov, A., Rakhimov, K., Abduraimova, D., Babaev, A., Melikuziyev, S. Hydrotransport of river sediments in hydroelelators. (2020) IOP Conference Series: Materials Science and Engineering, 869 (7). DOI: 10.1088/1757-899X/869/7/072003 
12. Arifjanov, A., Rakhimov, K., Abduraimova, D., Akmalov, S. Transportation of river sediments in cylindrical pipeline (2019) IOP Conference Series: Earth and Environmental Science, 403 (1). DOI: 10.1088/1755-1315/403/1/012154

13. Arifjanov, A., Apakhodjaeva, T., Akmalov, S. Calculation of losses for transpiration in water reservoirs with using new computer technologies. (2019) International Conference on Information Science and Communications Technologies: Applications, Trends and Opportunities, ICISCT 2019. DOI: 10.1109/ICISCT47635.2019.9011883

14. Arifjanov, A., Otaxonov, M., Samiev, L., Akmalov, S. Hydraulic calculation of horizontal open drainages (2019) E3S Web of Conferences, 97. DOI: $10.1051 / \mathrm{e} 3$ sconf/20199705039

15. Mudflows of Uzbekistan. T., Administration of the Hydrometeorological Service of Uzbekistan, 1965. - 33-37 p.

16. Arifjanov, A., Rakhimov, K., Abduraimova, D., Babaev, A., Melikuziyev, S. Hydrotransport of river sediments in hydroelelators. (2020) IOP Conference Series: Materials Science and Engineering, 869 (7). DOI: 10.1088/1757-899X/869/7/072003

17. Muratov, A., Melikuziev, S. Technology of formation of combined products of meliorative purpose (2020) IOP Conference Series: Materials Science and Engineering, 883 (1). DOI: $10.1088 / 1757-899 X / 883 / 1 / 012060$

18. Lee, A., Usmonov, T., Norov, B., Melikuziev, S.Advanced device for cleaning drain wells (2020) IOP Conference Series: Materials Science and Engineering, 883 (1).DOI: 10.1088/1757-899X/883/1/012181

19. Abduraimova, D., Atakulov, D., Ibragimova, Z., Apakhodjaeva, T. Evaluation of erosion and accumulative process with using Geoinformation systems in water resource management (2019) International Conference on Information Science and Communications Technologies: Applications, Trends and Opportunities, ICISCT 2019. DOI: $10.1109 /$ ICISCT47635.2019.9012020

20. Fatxulloyev, A., Gafarova, A., Otakhonov, M., Allayorov, D. The hydraulic efficiency of the soil channels. IOP Conference Series: Materials Science and Engineering, 2020, 883(1), 012042 doi:10.1088/1757-899X/883/1/012042

21. Rakhimov, Q., Allayorov, D., Ibragimova, Z. Increasing flow turbidity in pressure systems. (2020) IOP Conference Series: Materials Science and Engineering, 869 (7). DOI: $10.1088 / 1757-899 X / 869 / 7 / 072029$

22. Rakhimov, K., Ahmedkhodjaeva, Xoshimov, S. Theoretical bases of hydraulic mixture in round cylindrical pipelines (2020) IOP Conference Series: Earth and Environmental Science, 614 (1). DOI: 10.1088/1755-1315/614/1/012095 